\title{
Investigation of the Nanostructure and Wear Properties of PVD CrCuN Nanocomposite Coatings
}

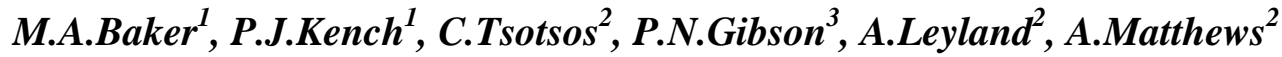 \\ ${ }^{1}$ School of Engineering, University of Surrey, Guildford, Surrey, GU2 7XH, UK \\ ${ }^{2}$ Department of Engineering Materials, University of Sheffield, Portobello Street, \\ Sheffield, S1 3JD, UK \\ ${ }^{3}$ Institute for Health and Consumer Protection, Joint Research Centre, I-21020 Ispra (VA) \\ - Italy
}

\begin{abstract}
This paper presents results on the PVD CrCuN nanocomposite coating system, in which the immiscibility of $\mathrm{Cr}$ (containing a supersaturation of nitrogen) and $\mathrm{Cu}$ offers the potential of a predominantly metallic (and therefore tough) nanocomposite, composed of small $\mathrm{Cr}(\mathrm{N})$ metallic and/or $\beta-\mathrm{Cr}_{2} \mathrm{~N}$ ceramic grains interdispersed in a (minority) $\mathrm{Cu}$ matrix. A range of $\mathrm{CrCuN}$ compositions have been deposited using a hot-filament enhanced unbalanced magnetron sputtering system. The stoichiometry and nanostructure have been studied by XPS, TEM, SEM and XRD. Hardness, wear resistance and impact resistance have been determined by nanoindentation, reciprocating-sliding and ball-onplate high-frequency impact. Evolution of the nanostructure as a function of composition and correlations of the nanostructure and mechanical properties of the $\mathrm{CrCuN}$ coatings are discussed. A nanostructure comprising of 1-3 nm $\alpha-\mathrm{Cr}(\mathrm{N})$ and $\beta-\mathrm{Cr}_{2} \mathrm{~N}$ grains separated by intergranular regions of $\mathrm{Cu}$ give rise to a coating with significantly enhanced resistance to impact wear.
\end{abstract}

Keywords: CrCuN, nanocomposite coatings, nanostructure, wear, PVD 


\section{Introduction}

It is well known that tailoring the nanostructure of coatings offers the potential of enhanced mechanical properties. The nanocomposite architecture of embedding hard nanocrystallites in an amorphous matrix, has become accepted as a design concept to increase the hardness, toughness and wear resistance of coatings for machine parts and tools [1-3]. Most ceramic materials used as protective coatings exhibit high hardness and elastic modulus. There is evidence to suggest that a high elastic modulus is often not ideal for improving the impact and sliding wear resistance of metallic components. For certain manufacturing operations (e.g. punching and forming), extending the lifetime of the machine tool requires a coating which has a strong resistance to fretting and the ability to deform without undergoing brittle or adhesive failure. Thus, for metallic substrates, desirable coating material properties are a combination of relatively high hardness and relatively low modulus: the latter being closely matched to that of the substrate [4].

It is within this context that metallic $\mathrm{CrCuN}$ coatings are being deposited. Rebholz et al have shown that adding up to 16 at.\% $\mathrm{N}$ to $\mathrm{Cr}$ yields coatings in which $\mathrm{N}$ is interstitially incorporated in $\alpha-\mathrm{Cr}$ [5]. Increasing the $\mathrm{N}$ content to between 16 and 29 at.\% gave rise to a dual phase $\alpha-\operatorname{Cr}(\mathrm{N})+\beta-\mathrm{Cr}_{2} \mathrm{~N}$ structure. Both single phase $\operatorname{Cr}(\mathrm{N})$ and dual phase $\operatorname{Cr}(\mathrm{N})$ $+\mathrm{Cr}_{2} \mathrm{~N}$ coatings offer good impact resistance, the former also exhibiting little evidence of radial cracking around the impact crater. By adding $\mathrm{Cu}$ to $\mathrm{Cr}(\mathrm{N})$, the aim is to deposit coatings having a structure of $\mathrm{Cr}(\mathrm{N})$ nanocrystallites inderdispersed within a minority $\mathrm{Cu}$ matrix. There is a thermodynamic driving force for immiscible phases in a coating system to separate. In the $\mathrm{Cr}-\mathrm{Cu}$ system, $\mathrm{Cr}$ prefers to adopt a b.c.c. and $\mathrm{Cu}$ a f.c.c. structure. 
The equilibrium phase diagram shows only a very small solubility of $\mathrm{Cr}$ in $\mathrm{Cu}$ [6]. However, it was reported previously that metastable $\mathrm{Cr}-\mathrm{Cu}$ single phase structures can be formed over a wide composition range using PVD methods [7-9]. Previous work on $\mathrm{CrCuN}$ coatings deposited at a substrate temperature of approximately $200^{\circ} \mathrm{C}$, in which the $\mathrm{Cu}$ concentration was varied from 2 to 20 at.\%, showed no clear evidence of $\mathrm{Cu}$ phase formation [10]. In this paper, the deposition temperature is increased to $300-350^{\circ} \mathrm{C}$ and $\mathrm{Cu}$ concentrations increased to over 55 at.\%. The nanostructure of these coatings is examined using TEM, XRD and XPS with mechanical properties evaluated from reciprocating-sliding, impact and abrasive wear tests.

\section{Experimental}

$\mathrm{CrCuN}$ coatings were deposited by reactive unbalanced magnetron co-sputtering of $\mathrm{Cr}$ and $\mathrm{Cu}$ onto Si wafer, AISI 316 stainless-steel and M2 tool-steel substrates. The samples were sequentially pre-cleaned ultrasonically in acetone, isopropyl alcohol and methylated spirits ( 5 minutes each) and furnace dried at $120^{\circ} \mathrm{C}$ for $30 \mathrm{~min}$. The samples were radiantly heated to approximately $300^{\circ} \mathrm{C}$ with the aid of a $2 \mathrm{~kW}$ resistive heater, prior to sputter cleaning for $20 \mathrm{~min}$. at $5 \mathrm{~Pa}$ argon pressure, with the substrate bias at $-700 \mathrm{~V}$ and $\sim 0.5 \mathrm{~mA} / \mathrm{cm}^{2}$ substrate current density. The coating process was carried out at $3.5 \mathrm{mTorr}$ Ar pressure with a $10 \mathrm{sccm} \mathrm{N}_{2}$ flow rate. Two $380 \mathrm{~mm}$ x $100 \mathrm{~mm}$ x $6.5 \mathrm{~mm}$ rectangular sputter targets (one $\mathrm{Cr}$ and one $\mathrm{Cu}$ ) were used, powered respectively at $1.5 \mathrm{~kW}$ and 0.15 $\mathrm{kW}$; the substrate bias was set at $-100 \mathrm{~V}$ with $\sim 0.3 \mathrm{~mA} / \mathrm{cm}^{2}$ substrate current density. The coatings were deposited at a substrate temperature of $300^{\circ} \mathrm{C}$, rising to $350^{\circ} \mathrm{C}$ by the end of the deposition period. The $\mathrm{Cr}$ and $\mathrm{Cu}$ sputter targets were positioned on adjacent walls of the reaction chamber. To adjust the $\mathrm{Cr} / \mathrm{Cu}$ ratio of the alloys, the specimens were placed towards the centre of the deposition chamber at varying intervals facing the 
$\mathrm{Cr}$ and $\mathrm{Cu}$ targets which were each positioned at an angle of 45 degrees to the substrate holder. The specimens were placed such that coating 1 was nearest to the $\mathrm{Cr}$ target and coating 6 nearest to the $\mathrm{Cu}$ target.

X-ray Photoelectron Spectroscopy (XPS) was performed on a VG Scientific Sigma Probe employing a non-monochromated $\mathrm{Mg}-\mathrm{K} \alpha$ source and a spherical sector analyser. A 3 $\mathrm{keV} \mathrm{Ar}^{+}$ion beam was used to remove the surface oxide layer. Survey spectra of the bulk coating were then recorded at $50 \mathrm{eV}$ pass energy and narrow scans at $20 \mathrm{eV}$ pass energy (step width of $0.1 \mathrm{eV}$ ). Quantification was performed after a Shirley background subtraction using instrument modified Scofield sensitivity factors. XRD was performed using a Philips X-ray diffractometer, employing monochromated $\mathrm{Cu}-\mathrm{K} \alpha$ radiation at a tube voltage of $40 \mathrm{keV}$ and current of $24 \mathrm{~mA}$. A LaB 6 Philips CM200 operated at 200 $\mathrm{keV}$ was employed for the TEM work. Preparation of the cross-sectional TEM specimens involved using a Gatan Precision Ion Polishing System (PIPS) ion beam thinner with the beam incident first at 15 degrees, before a final thinning at 4 degrees. Two guns were used, one above and one below the specimen, each operating at an accelerating voltage of $5 \mathrm{keV}$ and current of $1 \mathrm{~mA}$. Plan view specimens were prepared by thinning through the substrate, leaving the surface of the coating sufficiently thin for investigation.

For coatings deposited on AISI 316 substrates, the wear resistance properties were determined as follows. Reciprocating-sliding wear was measured using a low frequency (5 Hz) reciprocating test apparatus, with a $10 \mathrm{~mm}$ diameter SAE 52100 ball counterface, at $10 \mathrm{~N}$ normal load, for $500 \mathrm{~m}$ sliding distance at a temperature of $23 \pm 2{ }^{\circ} \mathrm{C}$ and $50 \pm 5 \%$ humidity. The average wear-scar cross-sectional area was measured using a Dektak 3ST surface profilometer and the wear rate calculated. To determine impact wear resistance, a 
dynamic ball-on-plate impact tester, using a $10 \mathrm{~mm}$ diameter WC-6Co ball, impact force $1000 \mathrm{~N}$, frequency $8 \mathrm{~Hz}$, was employed. Three samples of each coating were tested for $10^{5}$ impact cycles. The impact crater diameter was measured for each and the average impact volume calculated.

\section{Results}

\subsection{Composition (XPS)}

Six $\mathrm{CrCuN}$ coatings with increasing $\mathrm{Cu}$ content were examined. The relative compositions and binding energies of the $\mathrm{Cr} 2 \mathrm{p}_{3 / 2}, \mathrm{Cu} 2 \mathrm{p}_{3 / 2}$ and $\mathrm{N} 1 \mathrm{~s}$ peaks determined by XPS are given in Table 1. The $\mathrm{Cu}$ concentration increased from 1.8 at. $\%$ for coating 1 to 55.5 at. $\%$ for coating 6 . The $\mathrm{N}$ concentration remained moderately constant, varying from 18 to 23 at.\% (except for coating 6, where the high $\mathrm{Cu}$ content led to a reduction in the $\mathrm{N}$ concentration to 14 at.\%). The $\mathrm{Cr} / \mathrm{N}$ ratios are also given in Table 1 . In this ternary system, rather than using nitrogen concentration alone, the $\mathrm{Cr} / \mathrm{N}$ ratio is a more useful gauge of the critical level of $\mathrm{N}$ supersaturation in $\mathrm{Cr}$ required to precipitate $\beta-\mathrm{Cr}_{2} \mathrm{~N}$.

\subsection{Diffraction (XRD and TEM)}

The XRD patterns are presented in Figure 1. Coating 1 has the highest $\mathrm{Cr}$ concentration and the XRD pattern is dominated by the single $\alpha-\mathrm{Cr}$ (110) peak. Consequently, the 18 at.\% $\mathrm{N}$ appears to be mainly incorporated interstitially in the $\alpha-\mathrm{Cr}$ phase. There is a pronounced $\mathrm{Cr}$ (110) peak shift to higher angles, indicative of a slightly reduced lattice parameter, probably due both to the incorporation of $\mathrm{N}$ in the crystallites and in-plane stresses as a result of the deposition process. Coating 2 shows the clear emergence of the $\beta-\mathrm{Cr}_{2} \mathrm{~N}$ (200) peak in addition to the $\mathrm{Cr}(110)$ peak and similar patterns with both peaks 
present are seen for coatings 3 and 4. (In a randomly oriented material, the $\beta-\mathrm{Cr}_{2} \mathrm{~N}$ peak would be very weak, but $\mathrm{Cr}_{2} \mathrm{~N}$ coatings with a strong (200) orientation can result from reactive magnetron sputtering [11]). A slight decrease in the $\mathrm{Cr} / \mathrm{N}$ ratio (and total supersaturation of $(\mathrm{Cu}+\mathrm{N})$ in $\mathrm{Cr})$ has resulted in the precipitation of the $\mathrm{Cr}_{2} \mathrm{~N}$ phase in addition to $\mathrm{Cr}(\mathrm{N})$. From coating 2 to coating 4 there is a progressive increase in the $\mathrm{Cr}_{2} \mathrm{~N} / \mathrm{Cr}$ peak intensity ratio and an incremental shift of the $\mathrm{Cr}$ (110) peak to lower angles. This progressive shift of the $\mathrm{Cr}$ (110) peak back towards its elemental position can be explained by a reduction of the $\mathrm{N}$ concentration in the $\operatorname{Cr}(\mathrm{N})$ supersaturated phase as the $\mathrm{Cr}_{2} \mathrm{~N}$ phase fraction increases, together with a modification of the in-plane stress.

A dramatic change in spectral peak shape is observed for coatings 5 and 6 . For coating 5 , the XRD pattern exhibits one broad peak characteristic of an X-ray amorphous structure, the maximum occurring at approximately $46.1^{\circ}(\mathrm{d}$ spacing $=1.97 \AA)$. This maximum does not coincide with reflections for $\mathrm{Cr}, \beta-\mathrm{Cr}_{2} \mathrm{~N}$ or $\mathrm{Cu}$. However, as seen in Figure 2, electron diffraction results indicate the Cr-containing phases in this coating to in fact be nanocrystalline. The nanocrystallites of $\mathrm{Cr}$ and $\beta-\mathrm{Cr}_{2} \mathrm{~N}$ are very small and uniform in dimension, being approximately $2 \mathrm{~nm}$ in diameter (see Figure 3). Consequently, for coating 5, XRD appears unable to yield structural information about the Cr-containing phases, but does provide evidence for an intergranular $\mathrm{Cu}$ amorphous phase (see below). The spectrum of coating 6 is comprised of three overlapping peaks. The main peak at $50^{\circ}$ is indicative of nanocrystalline $\mathrm{Cu}$ phase formation. The intermediate peak has a maximum similar to that for coating 5 (at $46.1^{\circ}$ ) and the peak at low angles probably corresponds to the $\mathrm{Cu}$ (111) and/or $\beta-\mathrm{Cr}_{2} \mathrm{~N}$ (200) reflection. Thus, as the $\mathrm{Cu}$ concentration rises to 55 at.\%, nanocrystallites are able to form and a three-phase $\mathrm{Cu} / \mathrm{Cr}(\mathrm{N}) / \mathrm{Cr}_{2} \mathrm{~N}$ nanocrystalline structure emerges. 
Electron diffraction patterns for the coatings are shown in Figure 2. Coatings 1-4 show a good correlation with the XRD spectra. Only one phase, $\alpha-C r$, was observed in coating 1 and two phases, $\alpha-\mathrm{Cr}+\beta-\mathrm{Cr}_{2} \mathrm{~N}$, were clearly present in coatings 2-4. Faint and diffuse reflections were indexed to both $\mathrm{Cr}$ and $\mathrm{Cr}_{2} \mathrm{~N}$ phases for coating 5 (see section 3.4). In coating 6, in addition to the $\mathrm{Cr}$ and $\mathrm{Cr}_{2} \mathrm{~N}$ phases, some faint spots corresponding to the $\mathrm{Cu}(200)$ reflection are discernable.

\subsection{Bonding (XPS)}

Regarding chemical state and bonding information, there was no significant variation in the XPS core level peak positions and shapes between the coatings (Table 1). The $\mathrm{Cr}$ $2 \mathrm{p}_{3 / 2}$ peak position remained essentially unchanged at $574.4 \pm 0.1 \mathrm{eV}$. The value is similar to that obtained for pure $\mathrm{Cr}(574.5 \mathrm{eV}$ - as measured separately on our spectrometer) and $\mathrm{Cr}_{2} \mathrm{~N}(574.8 \mathrm{eV}$ [11]). Little variation is also observed for the $\mathrm{N} 1 \mathrm{~s}$ peak position. The $\mathrm{N} 1 \mathrm{~s}$ energies $(397.5 \pm 0.1 \mathrm{eV})$ are similar to the literature values for $\mathrm{Cr}_{2} \mathrm{~N}$ [12]. Nitrogen atoms will be present both as nitrides and at interstitial locations within the $\mathrm{Cr}$ phase. The $\mathrm{Cu} 2 \mathrm{p}_{3 / 2}$ peak shows a trend of decreasing binding energy with an increase in the $\mathrm{Cu}$ concentration (although the shift is very small). The binding energy progressively changes from $933.0 \mathrm{eV}$ to $932.7 \mathrm{eV}$ as the $\mathrm{Cu}$ concentration is increased. A similar variation of $933.1 \mathrm{eV}$ for low $\mathrm{Cu}$ concentration samples increasing to $932.8 \mathrm{eV}$ for high $\mathrm{Cu}$ concentrations was also observed in our previous work on $\mathrm{CrCuN}$ [10]. For coating 6, the $\mathrm{Cu}$ concentration reaches 56 at. \% and from the XRD results, $\mathrm{Cu}$ can be identified as a separate phase. Consequently, it can be understood that the $\mathrm{Cu}$ peak tends to a binding energy of that for elemental $\mathrm{Cu}$ (i.e. $932.7 \mathrm{eV}$ [13]) as clustering and eventual phase formation occurs with increasing $\mathrm{Cu}$ concentration. 


\subsection{Nanostructure (TEM)}

Bright field (BF) and dark field (DF) plan view TEM images for coatings 1-6 are given in Figure 2. It should be noted that the $\mathrm{BF}$ and $\mathrm{DF}$ images are not necessarily from identical regions. DF images were formed from the $\alpha-\mathrm{Cr}(110)$ and $\beta-\mathrm{Cr}_{2} \mathrm{~N}(200)$ reflections. All coatings are nanocrystalline, although there are substantial differences in the grain size and distribution between the various nanostructured phases present.

Coating 1 has a single phase metastable $\mathrm{Cr}(\mathrm{N})$ structure and a fairly uniform fine grain size. Coatings 2 and 3 exhibit a dual phase $\mathrm{Cr}(\mathrm{N})+\mathrm{Cr}_{2} \mathrm{~N}$ structure and a larger distribution of grain sizes. (A cross-sectional TEM DF image of coating 3 is also given in Figure 3 (a). The structure in this image is consistent with the DF plan view image and also shows evidence of columnar growth.) The larger grain size for coatings 2 and 3 is apparently caused by nucleation of $\beta-\mathrm{Cr}_{2} \mathrm{~N}$. Two possible effects can account for this: (a) the $\mathrm{Cr}_{2} \mathrm{~N}$ nanocrystallites once nucleated are able to grow from the surrounding $\alpha-\mathrm{Cr}(\mathrm{N})$ matrix and/or (b) the previously high concentration of $\mathrm{N}$ at the grain boundaries in $\mathrm{Cr}(\mathrm{N})$, which would be expected to hinder grain growth, is reduced on nucleation of $\mathrm{Cr}_{2} \mathrm{~N}$, facilitating grain coarsening. Coating 4 has a two phase $\mathrm{Cr}(\mathrm{N})+\mathrm{Cr}_{2} \mathrm{~N}$ structure but exhibits a finer grain size than coatings 2 and 3. Compared to the latter two coatings coating 4 has a higher $\mathrm{Cu}$ concentration (approximately 8 at. \%). In this case, the smaller grain size may be attributable to $\mathrm{Cu}$ segregating to grain boundaries and suppressing grain coarsening mechanisms.

The nanostructure of coating 5 is of particular interest. Consequently, in addition to the general plan-view images in Figure 2, a cross-section DF image, a second DF plan view 
image and a higher resolution plan view DF image are also given in Figures 3 (b), (c) and (d) respectively. The nanocrystallite phase composition cannot be unambiguously determined from the electron diffraction pattern, it is either purely $\operatorname{Cr}(\mathrm{N})$ or a mixture of $\mathrm{Cr}(\mathrm{N})+\mathrm{Cr}_{2} \mathrm{~N}$. However, the low $\mathrm{Cr} / \mathrm{N}$ ratio and high level of total supersaturation of $\mathrm{N}$ and $\mathrm{Cu}$ in $\mathrm{Cr}(\mathrm{N})$ most probably results in the formation of both phases. The nanostructure of this coating is very fine and uniform, with a consistent nanocrystallite size of 2-3 nm. There is strong preferential orientation of the nanocrystallites and columnar growth is evident from the DF cross-section image.

Even at 23 at. \%, $\mathrm{Cu}$ has not formed as a separate nanocrystalline phase in coating $5 . \mathrm{In}$ view of the low solid state miscibility of $\mathrm{Cu}$ with $\mathrm{Cr}$, the fine nanostructure and moderate deposition temperature, the majority of the $\mathrm{Cu}$ atoms may be expected to be located at grain boundaries and the position of the XPS $\mathrm{Cu} 2 \mathrm{p}_{3 / 2}$ peak is in accordance with $\mathrm{Cu}$ cluster formation. Thus a two component nanocrystalline/amorphous system can be assumed, the nanocrystalline components being either purely $\operatorname{Cr}(\mathrm{N})$, or $\operatorname{Cr}(\mathrm{N})+\beta-\mathrm{Cr}_{2} \mathrm{~N}$ and the amorphous component being $\mathrm{Cu}$. The relative atomic proportions of the two components are 77:23 ( $\mathrm{Cr}+\mathrm{N}): \mathrm{Cu}$.

Coating 6 has a three-phase structure. Increasing the $\mathrm{Cu}$ concentration to above 55 at.\% has led to its precipitation as a separate metallic phase. The $\mathrm{Cr}$ and $\mathrm{N}$ concentrations are now much lower, but as the $\mathrm{Cr} / \mathrm{N}$ ratio (at 2.2) is still low, both metallic $\mathrm{Cr}(\mathrm{N})$ and ceramic $\mathrm{Cr}_{2} \mathrm{~N}$ phases form in addition to $\mathrm{Cu}$. 


\subsection{Hardness \& wear resistance}

Nanoindentation data taken at a $20 \mathrm{mN}$ load is shown in Figure 4. The hardness for coating 1 is $25 \mathrm{GPa}$, rising to a maximum of $32 \mathrm{GPa}$ for coating 3 . From coating 4 to coating 6, the increasing $\mathrm{Cu}$ content causes the hardness to drop. The elastic modulus follows a similar trend. The H/E values vary between 0.085 and 0.01 .

The reciprocating-sliding and impact wear results are given in Figs. 5 and 6 respectively. In both tests, the best wear rates were observed for coatings 3-5. In reciprocating-sliding wear tests, mild polishing wear of the counterface ball rather than the coating was observed for positions 3 and 5. Coating 5 performed best in impact wear tests. The wear crater volume of $5 \times 10^{-3} \mathrm{~mm}^{3}$ was at least 3 times lower than for the other $\mathrm{CrCuN}$ coatings and about 35 times less than that observed for a single phase $\mathrm{Cr}(\mathrm{N})$ coating $(\mathrm{N}$ content 16 at.\%) [5]. The SEM micrographs for coatings 1-4 show greater delamination and radial cracking outside the crater than coatings 5 or 6 . The marked difference in performance between coatings 2 and 3 is difficult to rationalise considering their similar compositions and nanostructures. Nevertheless, the significant improvement in performance of nanostructured $\mathrm{CrCuN}$ coatings over a single-phase $\mathrm{Cr}(\mathrm{N})$ equivalent remains evident.

In abrasive wear tests (Fig. 7), the behaviour of the coatings is quite different. Only positions 2-5 were tested. The coating thicknesses decreased from coating 2 to 5 and this is reflected in the abrasion resistance results. Taking into account the influence of thickness variation, there appears to be little difference in the abrasion resistance, but coating 5 exhibited a slightly poorer performance than the other coatings. All coatings 
however exhibit substantially improved abrasion resistance over the uncoated AISI 316 steel substrate.

\section{Discussion}

\subsection{Formation of $\mathrm{Cr}(\mathrm{N})$ and $\mathrm{Cr}_{2} \mathrm{~N}$}

This set of $\mathrm{CrCuN}$ coatings has shown a very interesting evolution of nanostructure as a function of composition. Coating 1 is a single phase $\alpha-\operatorname{Cr}(\mathrm{N})$ coating with a grain size of approximately $3-5 \mathrm{~nm}$. As $\beta-\mathrm{Cr}_{2} \mathrm{~N}$ is precipitated in all other coatings, it would appear that approximately 18 at.\% (or a $\mathrm{Cr} / \mathrm{N}$ ratio of 4.3 ) corresponds to the saturation limit of $\mathrm{N}$ in $\mathrm{Cr}$. This is in good agreement with the 16 at.\% $\mathrm{N}$ saturation limit found by Rebholz et al [5], for 'pure' $\mathrm{Cr}(\mathrm{N})$ coatings sputter deposited under similar conditions.

Incorporation of $\beta-\mathrm{Cr}_{2} \mathrm{~N}$ into the coating structure has resulted from the decreasing $\mathrm{Cr} / \mathrm{N}$ ratio as the $\mathrm{Cu}$ content increases. However, as suggested by the formation ${ }^{\circ} \mathrm{Cr}_{2} \mathrm{~N}$ in coating 3 (also having a $\mathrm{Cr} / \mathrm{N}$ ratio of 4.3 ), the limiting $\mathrm{N}$ concentration may also be influenced by the total supersaturation concentration of $[\mathrm{N}+\mathrm{Cu}]$ in $\mathrm{Cr}$, so avoiding $\beta$ $\mathrm{Cr}_{2} \mathrm{~N}$ formation may require an even lower $\mathrm{N}$ concentration. The total supersaturation concentration will also be dependent on the degree of phase separation that has taken place. Taking purely the $\mathrm{Cr} / \mathrm{N}$ ratio as a measure of $\mathrm{N}$ concentration and a $\mathrm{Cr} / \mathrm{N}$ ratio of 4.3 as the limiting value, for coating 5, $(\mathrm{Cu}$ content 23 at. \%) an overall $\mathrm{N}$ concentration $<12.4$ at.\% would be required to form metallic $\mathrm{Cr}(\mathrm{N})$ as the only nanocrystalline phase.

Phase separation in nanocomposite coatings is dependent on both thermodynamic and kinetic considerations. From a kinetic viewpoint, surface mobility is critical and for any selected nanocomposite system composed of two stable phases, separation of the two phases will be promoted by increasing the deposition temperature. However, in the 
$\mathrm{CrCuN}$ system, the situation is complicated by the fact that the desired hard phase, $\mathrm{Cr}(\mathrm{N})$ is metastable. Metastable phase formation is promoted by reducing the deposition temperature. Consequently, to achieve the desired nanostructure requires a deposition temperature which enables both competing processes, metastable $\alpha-\mathrm{Cr}(\mathrm{N})$ phase formation and amorphous $a-\mathrm{Cu}$ phase separation, to simultaneously occur. Thus, compared to other nanocomposite systems composed solely of stable phases e.g. nc(Ti,Al)N/a-BN [1] or $n c-\mathrm{TiN} / a-\mathrm{Si}_{3} \mathrm{~N}_{4}$ [2], deposition of the metallic $n c-\mathrm{Cr}(\mathrm{N}) / a-\mathrm{Cu}$ system may be possible only in a relatively small deposition-parameter temperature window. The deposition temperature of $300-350^{\circ} \mathrm{C},-100 \mathrm{~V}$ substrate bias and $\sim 0.3$ $\mathrm{mA} / \mathrm{cm}^{2}$ current density combination of parameters employed here appear capable of forming purely $\mathrm{Cr}(\mathrm{N})$ when the $\mathrm{Cr} / \mathrm{N}$ ratio $>4.3$.

According to the $\mathrm{Cu}-\mathrm{Cr}$ phase diagram [14], the solubility of $\mathrm{Cu}$ in $\mathrm{Cr}$ is $\leq 0.02 \%$. However, it has been shown that sputtering at low temperature $\left(\leq 200^{\circ} \mathrm{C}\right)$ enables the range of $\mathrm{Cu}-\mathrm{Cr}$ mutual solubility to be extended, resulting in metastable phase formation over much of, or the whole, $\mathrm{Cu}-\mathrm{Cr}$ composition range [7-9]. In our previous set of $\mathrm{CrCuN}$ coatings, sputter deposited at $200^{\circ} \mathrm{C}$ with $\mathrm{Cu}$ contents up to 20 at.\%, elemental chromium and chromium nitride nanocrystalline phases were clearly identifiable in the XRD spectra but we concluded that $\mathrm{Cu}$ was probably incorporated in the $\mathrm{Cr}$-based phases rather than a nanocomposite structure developing [10]. Although the formation of an amorphous $\mathrm{Cu}$ intergranular phase and the location of most $\mathrm{Cu}$ atoms at grain boundaries cannot be unequivocally proven from the results obtained here, the very small grain size and form of nanostructure observed for coating 5 would suggest that a deposition temperature of $300-350^{\circ} \mathrm{C}$ is sufficiently high to effectively achieve separation into discrete $\mathrm{Cu}$ - and $\mathrm{Cr}$ based phases in this case. 


\subsection{Grain size effects}

In the general nanocomposite design proposed by Veprek [2], to achieve the desired mechanical properties, complete monolayer coverage of nanocrystallites by the amorphous phase is required. As the grain size changes, so does the surface area/volume ratio. Consequently, the critical concentration, $\mathrm{C}_{\mathrm{c}}$, of amorphous phase necessary to provide monolayer coverage, needs to be calculated for any particular grain size. For an idealised $n c-\mathrm{Cr} / a-\mathrm{Cu}$ system, calculations have been undertaken to determine the $\mathrm{C}_{\mathrm{c}}$ of $\mathrm{Cu}$ required to provide monolayer coverage of $\mathrm{Cr}$ as a function of grain size. As TEM or XRD can provide estimates of the grain diameter, it is appropriate to base the calculations on this as an input parameter. Calculations have been undertaken assuming the $\mathrm{Cu}$ monolayer to have one of two 2D packing densities: simple square packing or hexagonal close packing and results given for each case. Random close packing, (also known as dense random packing) has a packing density higher than simple square packing but lower than hexagonal close packing. A number of amorphous metal systems tend to such a structure $[15,16]$ and for the amorphous $\mathrm{Cu}$ layer considered here, random close packing is probably the most appropriate packing density. However, calculations of the surface area/volume ratio are not easily undertaken for random packing arrangements and are consequently not presented.

The surface area/volume ratio for any given grain diameter is independent of whether the grain shape is approximated to a cube or a sphere (although the total number of atoms is different). Consequently, if it is assumed that monolayer coverage corresponds to half the total surface area (due to grains sharing surfaces) then the amount of $\mathrm{Cu}$ required for 
monolayer coverage of grain diameter $d$, can be calculated for simple square packing from the following expression:

$\begin{aligned} & \text { No. of } \mathrm{Cu} \text { atoms for monolayer coverage } \\ & \text { No. of } \mathrm{Cr} \text { atoms in a cubic grain }\end{aligned}=\frac{3 d^{2} /(2 r)^{2}}{p d^{3} / V}=\frac{3 V}{4 p d r^{2}}$

where $r$ is the atomic radius (being taken as 0.125 and $0.128 \mathrm{~nm}$ for $\mathrm{Cr}$ and $\mathrm{Cu}$ respectively [17]), $p$ is the packing density (e.g. $68 \%$ for body centred cubic $\mathrm{Cr}$ ) and $V$ is the atomic volume. A similar expression is obtained for hexagonal close packing:

$\underline{\text { No. of } \mathrm{Cu} \text { atoms for monolayer coverage }}=$

No. of $\mathrm{Cr}$ atoms in a cubic grain

$\frac{3 d^{2} /\left(2 r \times \sqrt{(2 r)^{2}-r^{2}}\right)}{p d^{3} / V}=\frac{\sqrt{3} V}{2 p d r^{2}}$

The results are given in Table 2. The required $\mathrm{Cu}$ at.\% range for random close packing would be expected to lie within the simple square packing - hexagonal close packing range. These results should clearly be taken as approximations but give working estimates of the range of minimum theoretical concentrations required to form a complete 3D-interconnecting network of the monolayer, for a given nanograin size. Furthermore, as all nanocomposite systems will exhibit similar grain-volume/surface-area ratios as a function of grain size, the trend in concentrations of amorphous phase required for monolayer coverage with decreasing grain size, should be representative of all such systems. 
For $n c-\mathrm{TiN} / a-\mathrm{Si}_{3} \mathrm{~N}_{4}$ thin films, Veprek et al have also considered the effect of crystallite size on $\mathrm{Si}_{3} \mathrm{~N}_{4}$ surface coverage of TiN nanograins [18]. They concluded that the $\mathrm{Si}_{3} \mathrm{~N}_{4}$ surface coverage can be determined by multiplying the XPS Si $2 p$ intensity by the grain diameter $d$. Applying a similar rationale to this system, multiplication of the required $\mathrm{Cu}$ content for monolayer coverage by the grain size (values given in Table 2) should give a constant for differing grain sizes. As the grain size increases from $1-10 \mathrm{~nm}$, the product is however not constant, but shows a monotonic increase with grain size, demonstrating an inconsistency between the two methods of dealing with the effect of grain size. Although the approach of Veprek et al does provide a scaling in the amorphous phase fraction as a function of grain size, their methodology appears oversimplified.

Nevertheless, Veprek et al suggest that for $n c-\mathrm{TiN} / a-\mathrm{Si}_{3} \mathrm{~N}_{4}$ nanocomposites [18], at grain diameters of 3-4 nm, 17-23 mol.\% $\mathrm{Si}_{3} \mathrm{~N}_{4}$ corresponds to monolayer coverage of the grain. This is in reasonably good agreement with our calculations for the idealised $n c-\mathrm{Cr} / a-\mathrm{Cu}$ system, where a 2-3 nm grain size corresponds to an expected amorphous phase concentration of approximately 20 at. $\% \mathrm{Cu}$ for monolayer coverage.

From the results of the calculations given in Table 2, ignoring any effect of $\mathrm{N}$ incorporation in $\mathrm{Cr}$, and assuming that phase separation is complete and that all grain boundaries are equivalent, then coating 5, with a $\mathrm{Cu}$ content of 23.4 at. $\%$ and an average grain size of approximately $2-3 \mathrm{~nm}$, would have a sufficiently high $\mathrm{Cu}$ concentration for grain boundary monolayer coverage of the Cr-containing nanocrystalline phases.

\subsection{Coating Growth Mechanisms}


From the cross-sectional TEM images in Fig. 3, the $\mathrm{CrCuN}$ coatings can be seen to exhibit columnar growth. The columns of both coatings 3 and 5 have an average diameter of approximately $50 \mathrm{~nm}$ (Figures 3 (a) and 3 (b)) and grow vertically from the substrate. For coating 5, the strong preferential orientation of the small and uniform sized $\mathrm{Cr}$ based nanocrystallites in Figures 2 (j) and 3 (c) provide an interesting insight into the columnar growth mode. In TEM, 3D information is projected to form a 2D image. Consequently, it is reasonable to assume that the large irregular features in Figs. 2 (j) and 3 (c) (composed of many hundreds of nanocrystallites) correspond to individual columns. As the columns grow vertically, they extend laterally to produce fractal-like forms, very similar to 2-D sub-monolayer cluster model simulations at the percolation threshold $[19,20]$. Thus, the deposition conditions are such that lateral growth of the columns is developing in a random or disordered fashion.

The results in Table 2 indicate that $\sim 23$ at. $\% \mathrm{Cu}$ is sufficient for complete grain boundary monolayer coverage in a $n c-\mathrm{Cr} / a-\mathrm{Cu}$ nanocomposite. However, for coating 5 , distinct preferential orientation of the nanocrystallites is observed. The initiation of (essentially) new crystallites in the same orientation would be promoted by incomplete grain coverage rather than full monolayer coverage. Consequently, although 23 at. $\% \mathrm{Cu}$ is theoretically sufficient for monolayer coverage, in practice, the highly dynamic and chaotic solidification processes in such multi-component systems will most probably lead to clustering of the $\mathrm{Cu}$ at the grain boundaries rather than uniform monolayer coverage $[4,10,21]$.

Considering the conclusions drawn from our previous work on sputter deposited $\mathrm{CrCuN}$ coatings deposited at $200{ }^{\circ} \mathrm{C}$ [10], it seems likely that, even at the higher deposition 
temperatures employed here, the idealised nanocomposite structure is not actually being formed during growth. Instead, it is reasonable to expect a small percentage of $\mathrm{Cu}$ atoms remaining within the $\mathrm{Cr}$ based grains and the distribution of $\mathrm{Cu}$ at the grain boundaries to not be completely homogeneous.

To summarise, the analytical results suggest that for coating 5 we are approaching a nanostructure corresponding to $\alpha-\mathrm{Cr}(\mathrm{N})+\beta-\mathrm{Cr}_{2} \mathrm{~N}$ nanocrystallites (grain size 2-3 nm) separated by a $\mathrm{Cu}$-rich amorphous grain boundary layer. Much of the $\mathrm{Cu}$ is located at grain boundaries, but probably clustered rather than forming a uniform monolayer hence, the 'idealised' nanocomposite structure [18] is not fully developed. This coating is largely metallic in nature.

\subsection{Nanostructure / Mechanical-Property Correlations}

The $\mathrm{CrCuN}$ coatings show a range of nanostructures across the composition range. The best performing coating in both reciprocating-sliding and impact wear tests was coating 5. In this coating, the nanocomposite structure of $\mathrm{Cr}(\mathrm{N})+\mathrm{Cr}_{2} \mathrm{~N}$ nanocrystallites mostly interdispersed by an amorphous $\mathrm{Cu}$ intergranular layer offers a superior combination of mechanical properties to resist these wear processes. Hard nanocrystallites of interstitially-supersaturated metallic $\mathrm{Cr}(\mathrm{N})$ and ceramic $\beta-\mathrm{Cr}_{2} \mathrm{~N}$ will provide resistance to indentation. During impact wear, a metallic substrate will deform and the capability of the coating to behave in a similar manner is important in preventing delamination and cracking over many cycles. Consequently, although hardness is primary in the protection of the underlying material, fracture and delamination generally lead to premature coating failure. Thus, prolonged coating integrity and adhesion to the substrate are the most influential factors in extending the lifetime of the coating in impact wear applications. 
The presence of $\mathrm{Cu}$ at the grain boundaries will enlarge the grain boundary region, promoting grain boundary sliding and allowing local plastic deformation to occur. This may explain the general absence of delamination and radial cracking in the impact wear test results for coating 5. Furthermore, the general prevalence of metallic rather than ceramic bonding within the coating will enhance fracture toughness and act to lower the elastic modulus, improving adhesion.

In abrasive wear tests, coating 5 showed a slightly inferior performance than the other three coatings with lower $\mathrm{Cu}$ concentrations. This is perhaps not surprising, since in such abrasion tests there is negligible deformation of the substrate, fracture is not a common cause of early coating failure and hardness is the foremost property in the prevention of wear for such applications. $\beta-\mathrm{Cr}_{2} \mathrm{~N}$ is a phase with a high hardness and the $\beta-\mathrm{Cr}_{2} \mathrm{~N} / \mathrm{Cr}(\mathrm{N})$ ratio increases progressively from coatings 1 to 4 . Coatings 2 and 3 show good abrasion resistance, but in coatings 4 and 5 , the positive effect of $\beta-\mathrm{Cr}_{2} \mathrm{~N}$ is negated by the increasing $\mathrm{Cu}$ concentration, reducing the hardness and, particularly in the case of coating 5 , the abrasion resistance.

The excellent performance of coating 5 in impact and reciprocating-sliding tests is very encouraging. However, results of the nanostructural investigation suggest that for this coating the 'idealised' nanocomposite structure has not fully developed. Furthermore, many parameters are yet to be optimised for such systems, e.g. grain size and intergranular layer thickness. Consequently, significant further improvement in mechanical performance can be expected when the optimum composition and structure are attained. 


\section{Conclusions}

A range of $\mathrm{CrCuN}$ coatings, with a $\mathrm{N}$ concentration of approximately 20 at. $\%$ and $\mathrm{Cu}$ contents ranging from 2 to 56 at.\%, have been deposited by hot-filament enhanced reactive co-sputtering at a deposition temperature of $300-350{ }^{\circ} \mathrm{C}$. All coatings exhibit a nanocrystalline or nanocomposite structure. The nanostructure varies as a function of $\mathrm{Cu}$ content as follows:

(a) coating 1: at $\mathrm{Cu}$ contents below 2 at.\%, a single phase $\alpha-\mathrm{Cr}(\mathrm{N})$ structure is formed

(b) coatings 2-4: at $\mathrm{Cu}$ contents of 3-9 at.\%, a two phase $\alpha-\mathrm{Cr}(\mathrm{N})+\beta-\mathrm{Cr}_{2} \mathrm{~N}$ nanocrystalline structure is formed with $\mathrm{Cu}$ probably present at grain boundaries and within the nanocrystallites

(c) coating 5: at a $\mathrm{Cu}$ content of 23 at.\%, a two phase $\mathrm{Cr}(\mathrm{N})+\mathrm{Cr}_{2} \mathrm{~N}$ structure develops with a crystallite size of 2-3 nm. Much of the $\mathrm{Cu}$ is located at grain boundaries, but the idealised nanocomposite structure with complete grain coverage is not fully developed.

(d) coating 6: at a $\mathrm{Cu}$ content of 56 at.\%, a three-phase $\mathrm{Cu} / \mathrm{Cr}(\mathrm{N}) / \mathrm{Cr}_{2} \mathrm{~N}$ nanocrystalline structure is obtained.

Calculations for an idealised $n c-\mathrm{Cr} / a-\mathrm{Cu}$ nanocomposite structure show that, for a grain size of 2-3 nm, monolayer coverage of the $\mathrm{Cr}$ grains should be obtained at a $\mathrm{Cu}$ concentration of approximately 20 at. \%. However, the nanostructure of coating 5 suggests that not all the $\mathrm{Cu}$ has segregated to the grain boundaries and/or uniform monolayer formation does not occur in practice - hence intergranular coverage by the $a$ $\mathrm{Cu}$ phase is probably incomplete. 
In impact wear tests, coating 5, having a $n c-\left[\mathrm{Cr}(\mathrm{N})+\mathrm{Cr}_{2} \mathrm{~N}\right] / a-\mathrm{Cu}$ structure, shows an improvement by at least a factor of 3 over the other $\mathrm{CrCuN}$ coatings and is more than 30 times better than single phase $\operatorname{Cr}(\mathrm{N})$ [6]. This coating structure also performed best in reciprocating-sliding tests, but did not show improved abrasion resistance. The enhanced impact and reciprocating wear performance of coating 5 is attributed to the relatively high hardness (18 GPa) combined with excellent fracture toughness and adhesion to the substrate. For the $n c-\left[\mathrm{Cr}(\mathrm{N})+\mathrm{Cr}_{2} \mathrm{~N}\right] / a-\mathrm{Cu}$ structure, toughness and adhesion are enhanced by: (a) predominant metallic bonding (giving a high $\mathrm{H} / \mathrm{E}$ ratio); (b) the nanocomposite structure improving fatigue resistance and facilitating some plastic deformation by grain boundary sliding; (c) the ductility of $\mathrm{Cu}$. 


\section{Acknowledgements}

We would like to thank Professor Panos Tsakiropoulos and Dr Guosheng Shao for many fruitful discussions on this work. Thanks are expressed also to Mr. Marvin Joseph, for assistance with coating deposition and tribological testing. The authors at Surrey and Sheffield Universities gratefully acknowledge the financial support of the UK Engineering and Physical Sciences Research Council (EPSRC), under grant award numbers GR/R07981 and GR/N03495.

\section{References}

[1] M.A.Baker, S.Klose, C.Rebholz, A. Leyland, A.Matthews Surface and Coatings Technology 151-152 338 (2002)

[2] S. Veprek, J. Vacuum Science and Technology A, 172401 (1999)

[3] A.A.Voevodin, J.S.Zabinski Thin Solid Films 370223 (2000)

[4] A.Leyland, A.Matthews Wear, 2461 (2000)

[5] C.Rebholz, H.Ziegele, A.Leyland, A.Matthews Surface and Coatings Technology 115222 (1999)

[6] Phase Equilibria Diagrams A.E.McHale (Ed.), Borides, Carbides and Nitrides Vol.X, The American Ceramic Society, Westerville, OH (1994) p415

[7] A.G.Dirks, J.J.van den Brock J. Vacuum Science and Technology A 32618 (1985)

[8] H.Holleck Surface and Coatings Technology 36151 (1988)

[9] A.P.Payne, B.M.Clemens J. Mater. Res. 71370 (1992)

[10] M.A.Baker, P.J.Kench, M.C.Joseph, C.Tsotsos, A.Leyland, A.Matthews Surface and Coatings Technology 162222 (2003)

[11] S.M.Aouadi, D.M.Schultze, S.L.Rhode, K.-C.Wong, K.A.R.Mitchell Surface and Coatings Technology 140269 (2001) 
[12] O. Nishimura, K. Yabe, M. Iwaki J. Electron Spectroscopy and Related Phenomena 49335 (1989)

[13] Practical Surface Analysis Vol.1 Eds. D.Briggs and M.P.Seah, $2^{\text {nd }}$ Edition, Wiley, Chichester, UK (1990)

[14] Binary Alloy Phase Diagrams T.B.Massalski, J.L.Murray, L.H.Bannet and H.Baker (Eds.) ASM, Metals Park, OH, USA (1986)

[15] W.H.Wang, C.Dong, C.H.Shek Materials Science and Engineering R 4445 (2004)

[16] R.Zallen The Physics of Amorphous Solids John Wiley, New York, 1983

[17] CRC Handbook of Chemistry and Physics, D.R.Lide, (Ed.) CRC Press, Boca Raton, FL, USA (2003)

[18] S.Veprek, A.Niederhofer, K.Moto, T.Bolom, H-D.Männling, P.Nesladek, G.Dollinger, A.Bergmaier Surface and Coatings Technology 133-134 152 (2000)

[19] P.Jensen, A-L.Barabasi, H.Larralde, S.Havlin, H.E.Stanley Chaos, Solitons and Fractals 6227 (1995)

[20] F.Family Physica A, 266173 (1999)

[21] A.Leyland, A.Matthews Surface and Coatings Technology 177-178 317 (2004) 
Table 1: Relative atomic percentages of $\mathrm{Cr}, \mathrm{Cu}$ and $\mathrm{N}$; and the positions of the major photoelectron peaks as determined by XPS for the six $\mathrm{CuCr}(\mathrm{N})$ coatings.

\begin{tabular}{|c|c|c|c|c|c|c|c|c|}
\hline \multirow{2}{*}{ Sample } & \multicolumn{4}{|c|}{ Atomic Percent } & \multirow{2}{*}{ Stoichiometry } & \multicolumn{3}{|c|}{ XPS Peak Position (eV) } \\
\cline { 8 - 10 } & $\mathbf{C r}$ & $\mathbf{C u}$ & $\mathbf{N}$ & $\mathbf{C r} / \mathbf{N}$ & & $\mathrm{Cr} 2 \mathrm{p}_{3 / 2}$ & $\mathrm{Cu} 2 \mathrm{p}_{3 / 2}$ & $\mathrm{~N} 1 \mathrm{~s}$ \\
\hline Coating 1 & 79.8 & 1.8 & 18.4 & 4.3 & $\mathrm{CrCu}_{0.02} \mathrm{~N}_{0.24}$ & 574.3 & 933.0 & 397.5 \\
\hline Coating 2 & 76.4 & 3.0 & 20.6 & 3.7 & $\mathrm{CrCu}_{0.04} \mathrm{~N}_{0.27}$ & 574.4 & 932.9 & 397.6 \\
\hline Coating 3 & 78.5 & 3.3 & 18.2 & 4.3 & $\mathrm{CrCu}_{0.02} \mathrm{~N}_{0.19}$ & 574.3 & 932.9 & 397.6 \\
\hline Coating 4 & 70.5 & 8.4 & 21.1 & 3.3 & $\mathrm{CrCu}_{0.12} \mathrm{~N}_{0.30}$ & 574.3 & 932.8 & 397.6 \\
\hline Coating 5 & 53.3 & 23.3 & 23.4 & 2.3 & $\mathrm{CrCu}_{0.44} \mathrm{~N}_{0.44}$ & 574.4 & 932.7 & 397.5 \\
\hline Coating 6 & 30.7 & 55.5 & 13.8 & 2.2 & $\mathrm{CrCu}_{1.81} \mathrm{~N}_{0.45}$ & 574.3 & 932.7 & 397.4 \\
\hline
\end{tabular}

Table 2: The atomic concentration of $\mathrm{Cu}$ required to give monolayer coverage of $\mathrm{Cr}$ grains in a $\mathrm{Cr} / \mathrm{a}-\mathrm{Cu}$ nanocomposite coating. The range of $\mathrm{Cu}$ at.\% required corresponds to different $\mathrm{Cu}$ monolayer packing densities (associated with simple cubic packing or the closer packed hcp/fcc arrangement).

\begin{tabular}{|c|c|c|c|c|c|}
\cline { 2 - 6 } \multicolumn{1}{c|}{} & \multicolumn{5}{c|}{ Cr grain size (nm) } \\
\cline { 2 - 6 } \multicolumn{1}{c|}{} & 1 & 2 & 3 & 5 & 10 \\
\hline $\begin{array}{l}\text { Cu at. \% } \\
\text { required }\end{array}$ & $35.6-38.9$ & $21.6-24.2$ & $15.5-17.5$ & $10.0-11.3$ & $5.2-6.0$ \\
\cline { 2 - 6 } & $\sim 4$ & $\sim 8$ & $\sim 12$ & $\sim 20$ & $\sim 80$ \\
\cline { 2 - 5 } & \multicolumn{5}{|c}{ Cr grain width (No. of atoms) } \\
\hline
\end{tabular}




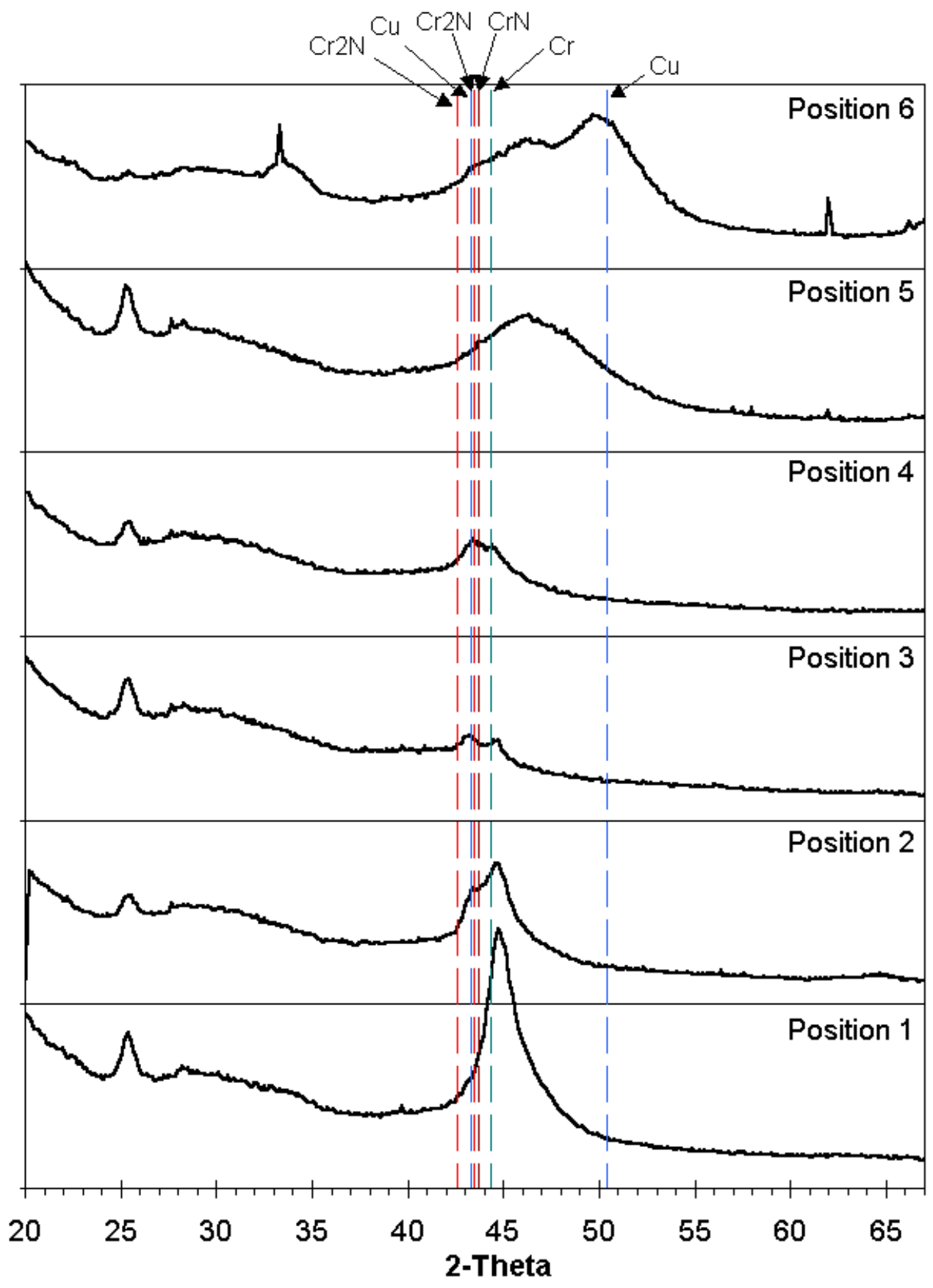

Figure 1: XRD spectra of the $\mathrm{CuCr}(\mathrm{N})$ coatings 

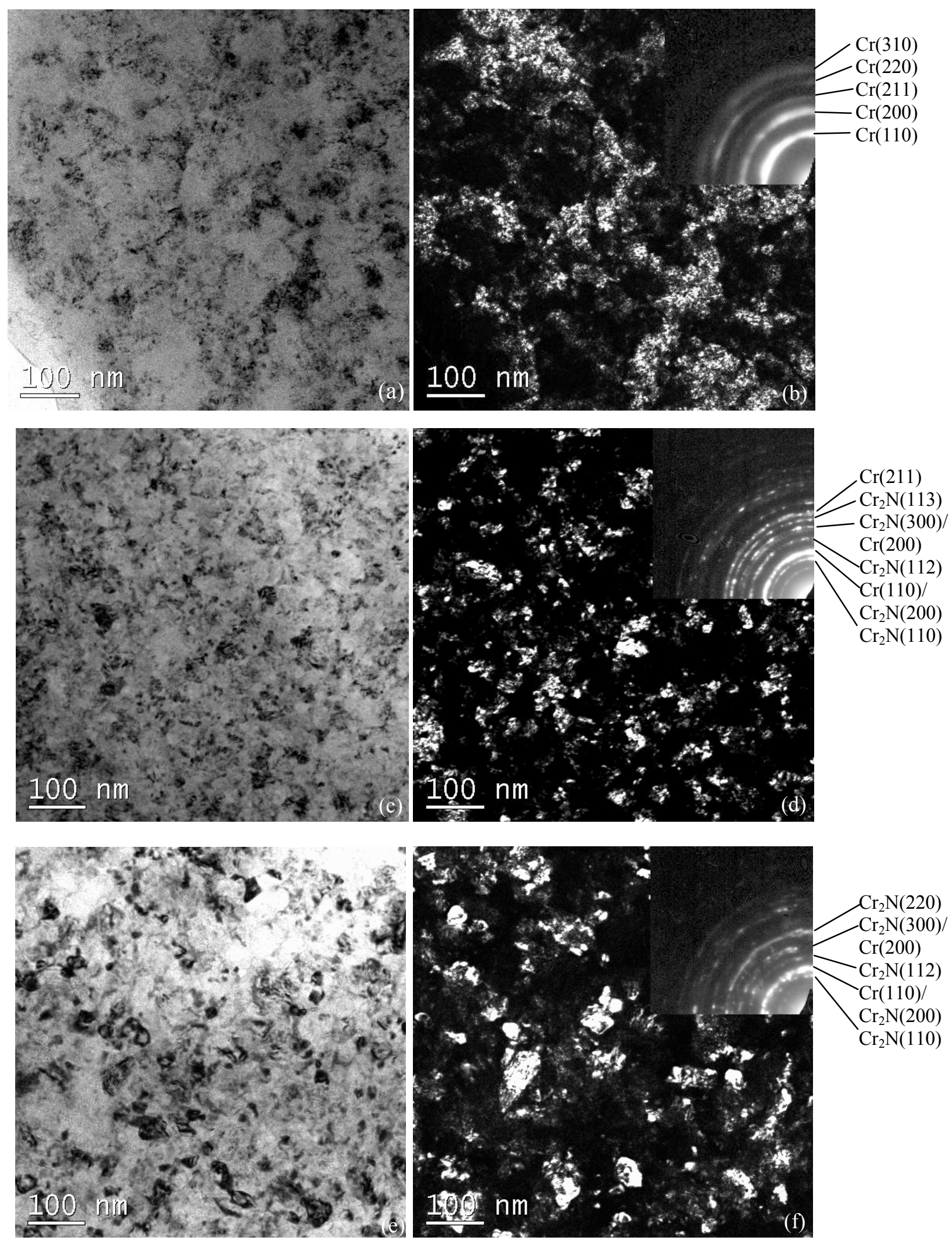

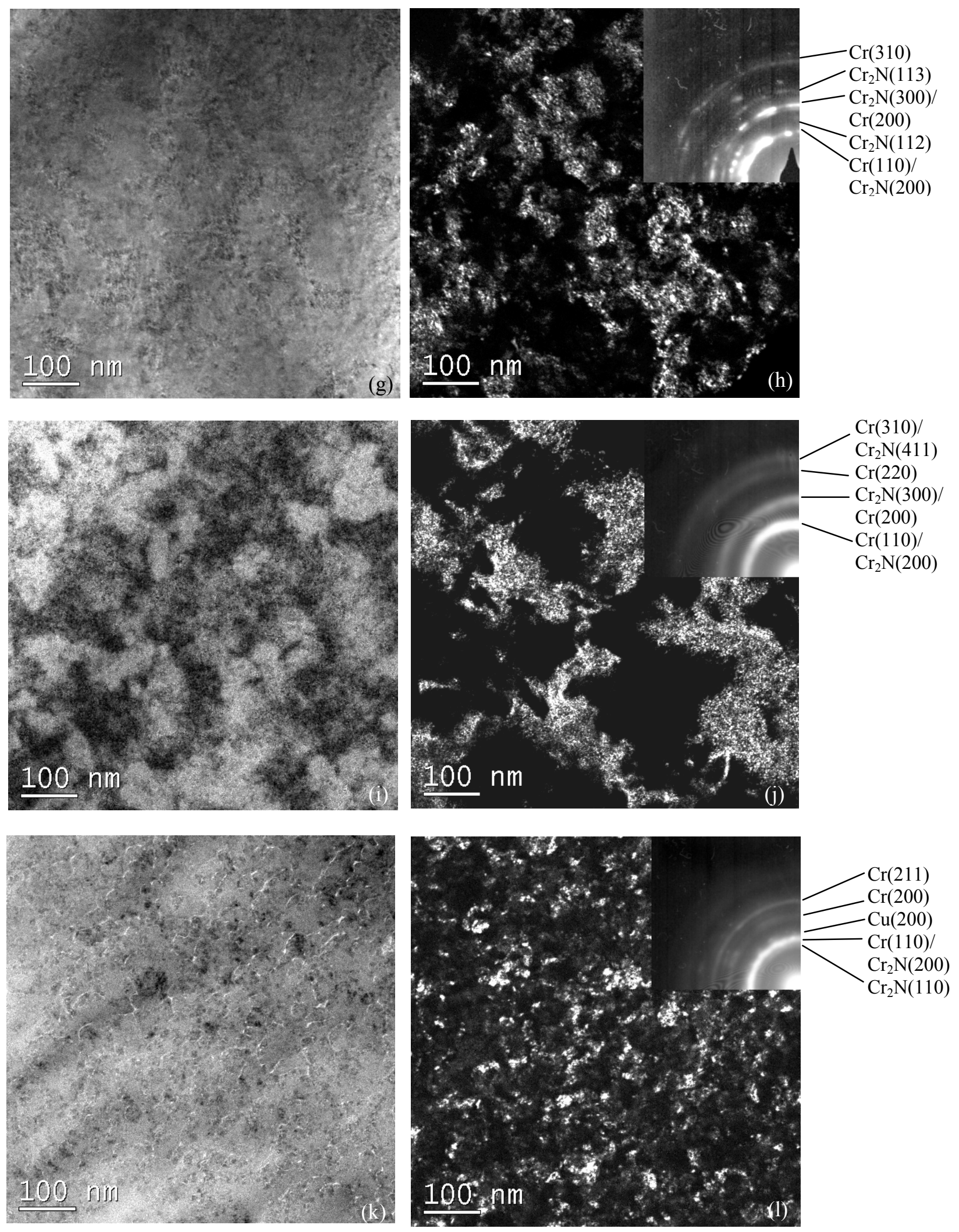

Figure 2 : Plan view bright field (left) and dark field (right) TEM micrographs of $\mathrm{CuCr}$ (N) coatings. The figure progresses numerically from coating 1 ((a) and (b)) to coating 6 ((k) and (1)). 

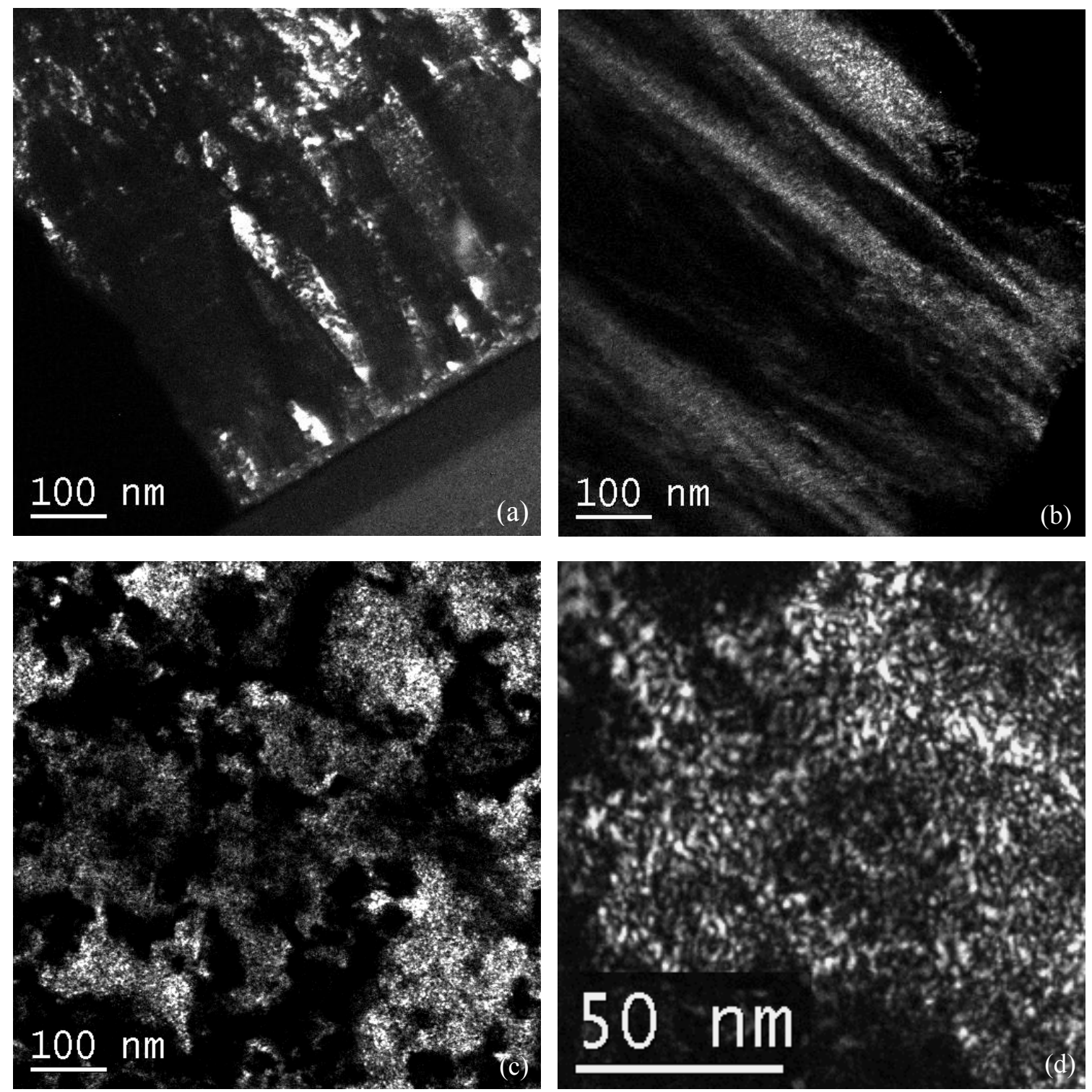

Figure 3: TEM dark field images of the $\mathrm{CuCr}(\mathrm{N})$ coatings (a) cross-section coating 3; (b) cross-section coating 5; plan-view coating 5; (d) high resolution plan-view coating 5 


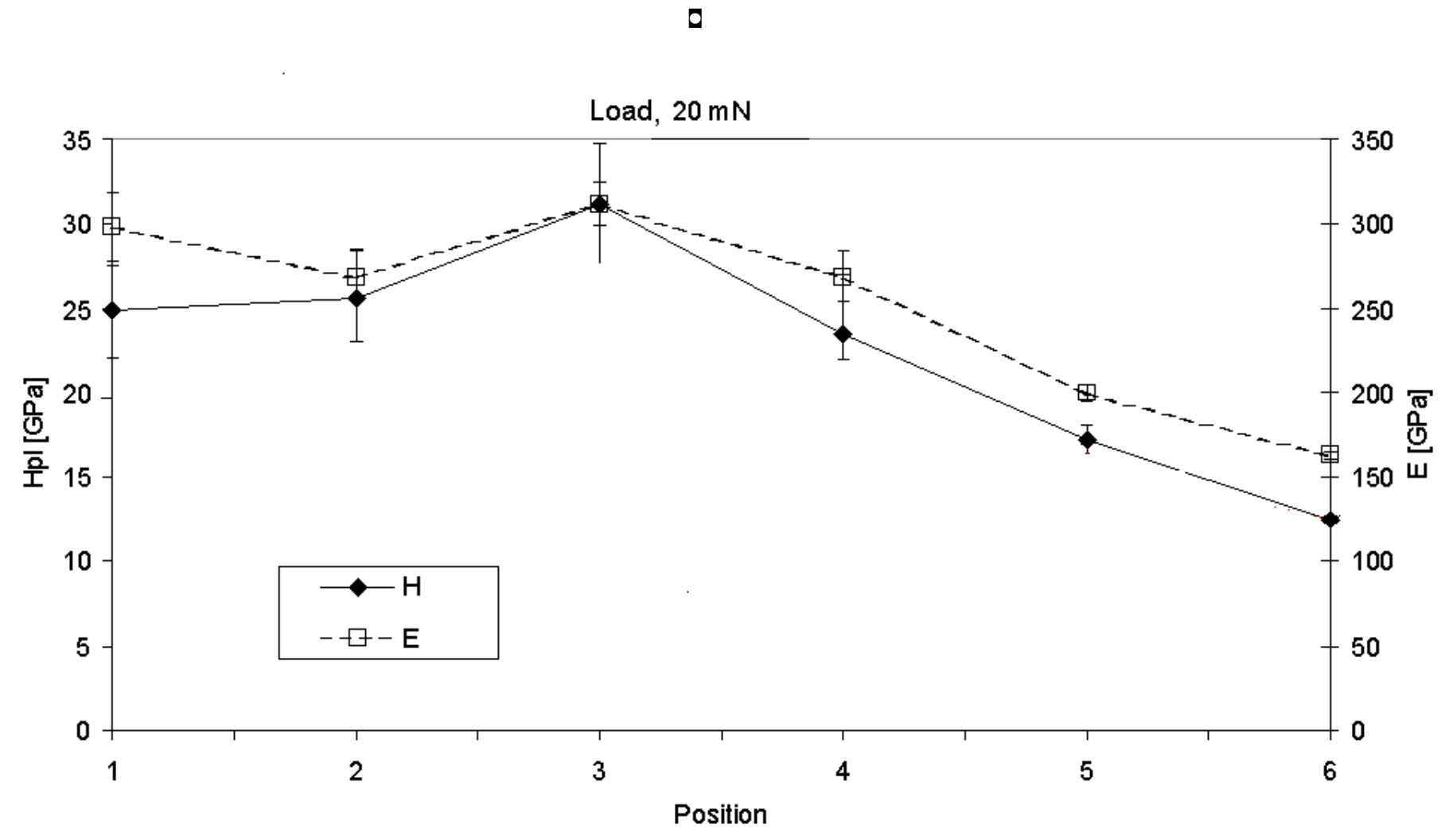

Figure 4: Nanoindentation hardness and elastic modulus results for coatings 1-6 determined at a load of $20 \mathrm{mN}$ 
Knoop Microhardness

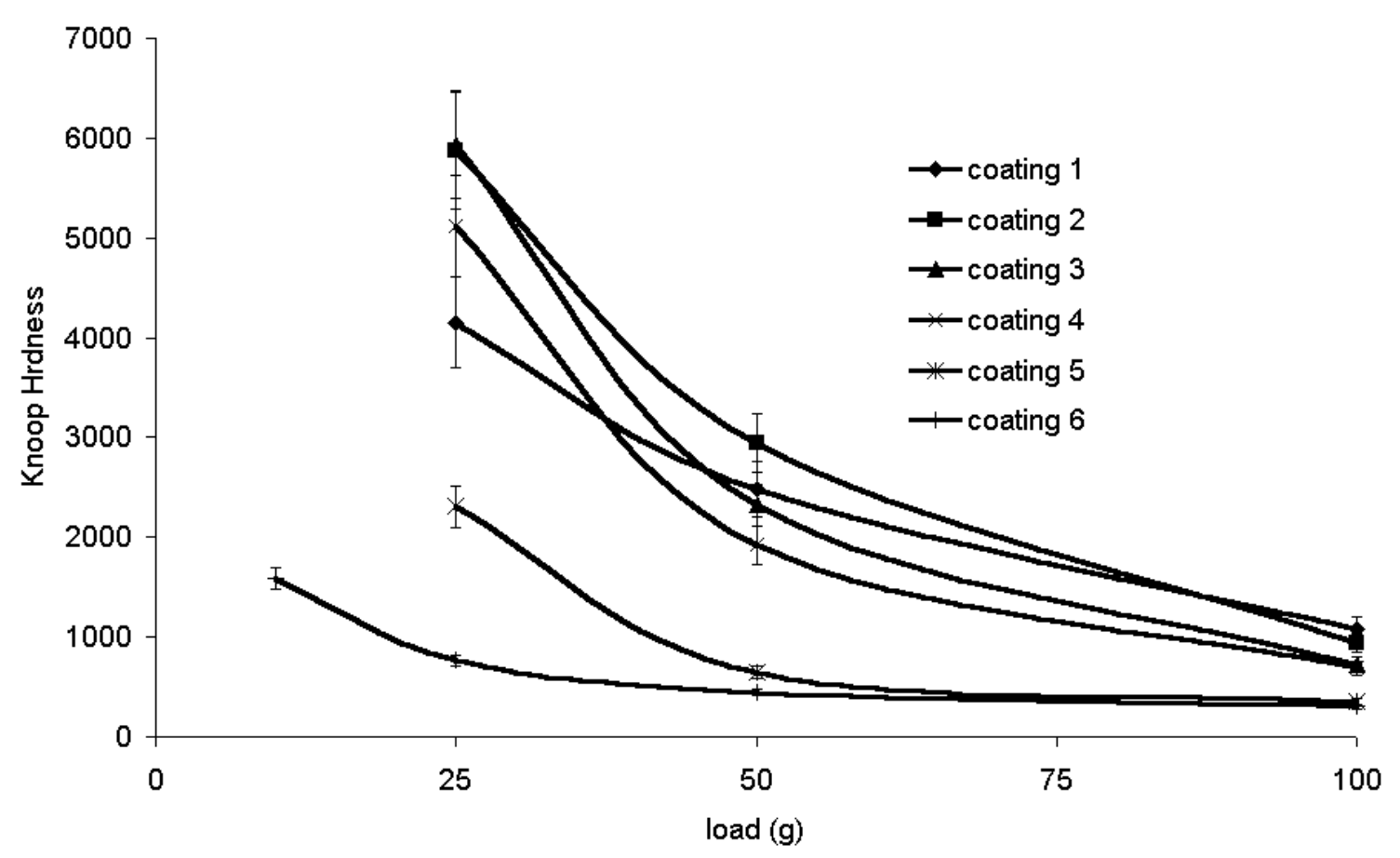

Figure 5: Knoop microhardness results for coatings 1-6 at loads between 25 and $100 \mathrm{~g}$. 


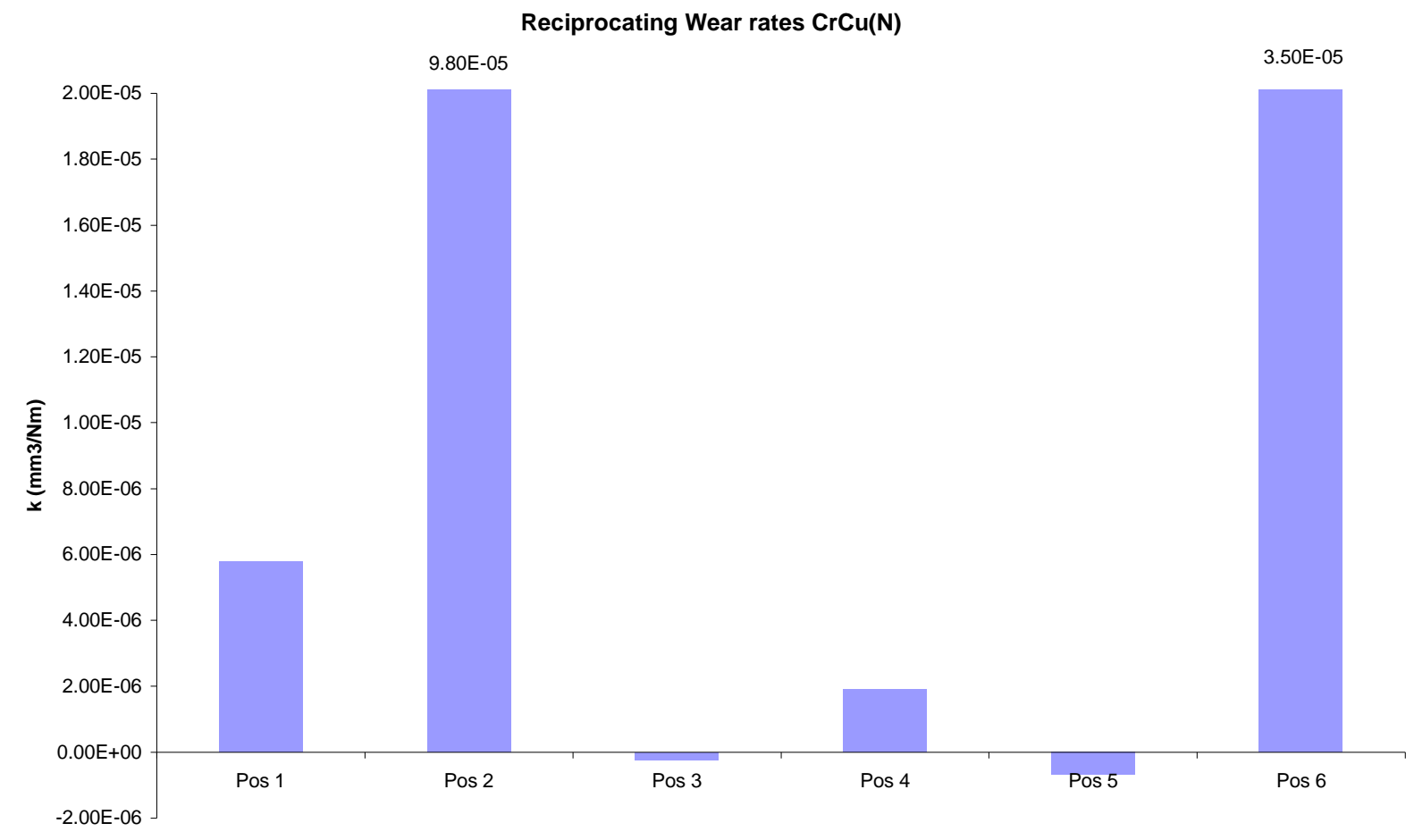

Figure 6: Reciprocating wear rates for coatings 1-6 


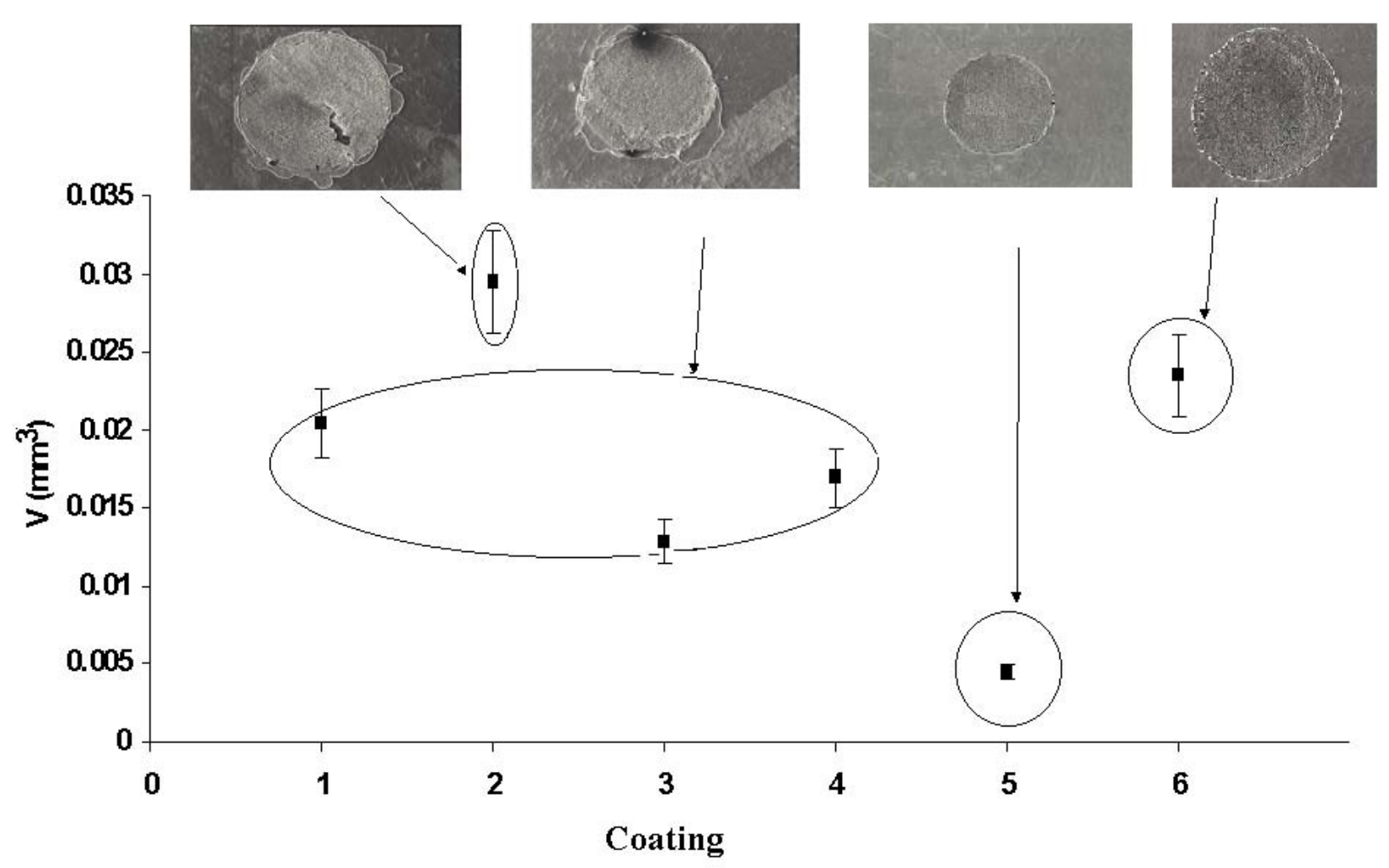

Figure 7: Impact wear results for the $\mathrm{CuCr}(\mathrm{N})$ coatings. WC-4Co ball counterface, 100,000 cycles, $1000 \mathrm{~N}$ load. 
Micro-abrasion Wear rates

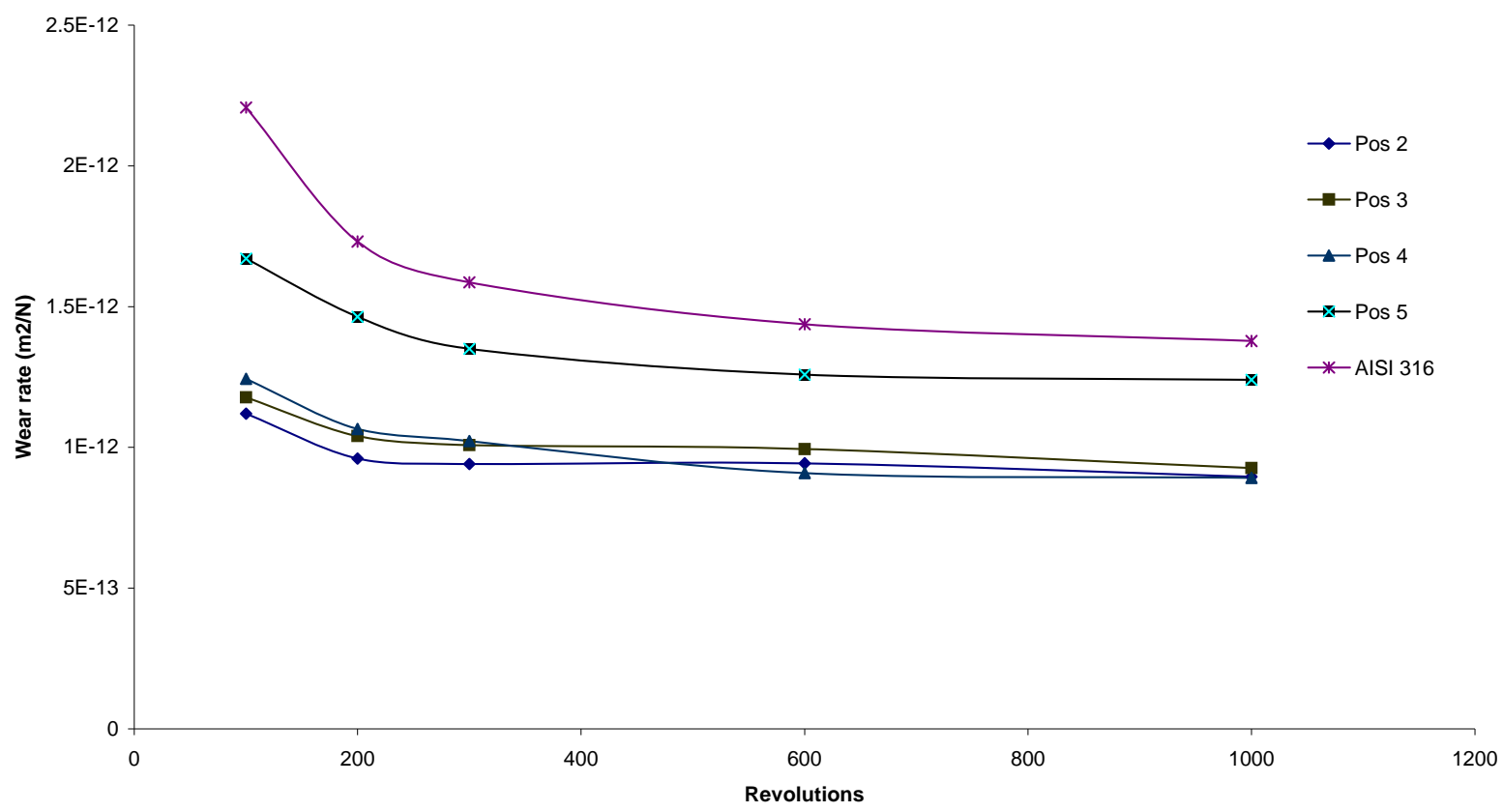

Figure 8: Abrasion wear results for coatings 2-5 
